\title{
Organic molecular and inorganic isotope records of Cenozoic topography, ecosystem and climate evolution of the Southern Central Andes
}

\author{
HREN, M.T ${ }^{1}$., BRANDON, M. ${ }^{2}$, FEnNELL, L. ${ }^{3}$, SMOLEN,
} J. ${ }^{1}$, SUPER, J. ${ }^{2}$

${ }^{1}$ Department of Geosciences, University of Connecticut, Storrs, CT 06269.hren@uconn.edu; jonathan.smolen@uconn.edu

${ }^{2}$ Geology \& Geophysics, Yale University, New Haven, CT 06520. Mark.brandon@yale.edu; james.super@yale.edu ${ }^{3}$ Instituto de Estudios Andinos, Universidad de Buenos Aires-CONICET, Buenos Aires, Argentina. lucasfennell90@gmail.com

The Andes are part of the longest mountain range on earth and their evolution has influenced global climate, weathering, and ecosystems since the Cretaceous. We analyzed the distribution and $\delta^{2} \mathrm{H}$ and $\delta^{13} \mathrm{C}$ of plant-derived organic biomarkers, the $\delta^{2} \mathrm{H}$ of volcanic glass, and the distribution of soil-derived glycerol dialkyl glycerol tetraethers from Cenozoic sediments in the Malargüe Basin of Argentina $\left(\sim 35^{\circ} \mathrm{S}\right)$. Organic molecular and inorganic data were measured to reconstruct Cenozoic changes in precipitation isotopes, temperature, moisture deficit, and ecosystems on the eastern flank of the Southern Central Andes. Two variables (precipitation isotopes and temperature) are strongly related to the topography of an orogen through isotopic distillation of precipitation during rainout and changes in temperature with elevation. However, molecular biomarkers also provide key information about climate and aridity through time. We show that organic biomarker and volcanic glass $\delta^{2} \mathrm{H}$ data from the Malargüe basin record late Cenozoic reduction of orographic lifting of airmasses associated with local downdrop of the basin. In addition, molecular data reflect long-term shifts in moisture deficit and plant water stress that are consistent with regional patterns of changing climate and aridity due to late Cenozoic cooling. Soilderived tetraether lipid records mirror the patterns observed in organic molecular and inorganic isotope data, yet record temperatures that are unrealistic. These data highlight the complexity of universally applying the soil GDGT proxy to all terrestrial systems. In total, combined organic and inorganic data highlight the importance of multi-proxy records to produce a coherent representation of long-term ecosystem and climate change in a region impacted by evolving climatic and tectonic boundary conditions. 